\title{
Differential intraluminal flow turbulence: a marker of aortic dissection
}

\author{
Ravindran Rajendran, Bhupinder Singh, Shivakumar Bhairappa, C N Manjunath \\ Department of Cardiology, Sri Jayadeva Institute of Cardiovascular Sciences and Research, Bangalore, Karnataka, India
}

Correspondence to Dr Ravindran R, rravi_dr@rediffmail.com

\section{DESCRIPTION}

A 54-year-old hypertensive patient presented with chest and back pain for the last $4 \mathrm{~h}$. Physical examination was normal except for a blood pressure of $180 / 100 \mathrm{~mm} \mathrm{Hg}$ in both upper limbs. ECG and a chest x-ray were normal, cardiac biomarkers were negative. A bedside transthoracic echocardiogram (TTE) showed concentric left ventricular hypertrophy with normal left ventricular function, normal valves and no evidence of pericardial effusion. The aortic arch as visualised from suprasternal view was also unremarkable except for a differential intraluminal turbulence on colour Doppler, just distal to the origin of the left subclavian artery (video 1). Pulse Doppler interrogation showed dual flow velocities within the aortic lumen, a normal forward flow pattern in the outer part and a sluggish flow pattern in the inner part (figure 1). Based on this, a descending aortic dissection was suspected, that was confirmed by a CT aortogram. The volume rendered imaging showed Stanford type B acute aortic dissection extending upto bilateral common iliac arteries (figure 2). The patient was managed conservatively as symptoms subsided with control of blood pressure and there was no major organ compromise.

TTE is considered inferior to transoesophageal echocardiography for aortic dissection. ${ }^{1}$ But, TTE being available at the bedside in most of the emergency departments could give a valuable clue pointing to the cause of chest pain, even in patients with symptoms not typical for aortic dissection as many such patients are seen in the chest pain clinic. Routine Doppler interrogation of aorta during TTE should be a part of the screening echo as it may be rewarding as in our case. Doppler interrogation showing differential intraluminal turbulence with dual flow velocities despite non-visualisation of flap would still suggest a dissection and the need for a more specific investigation.

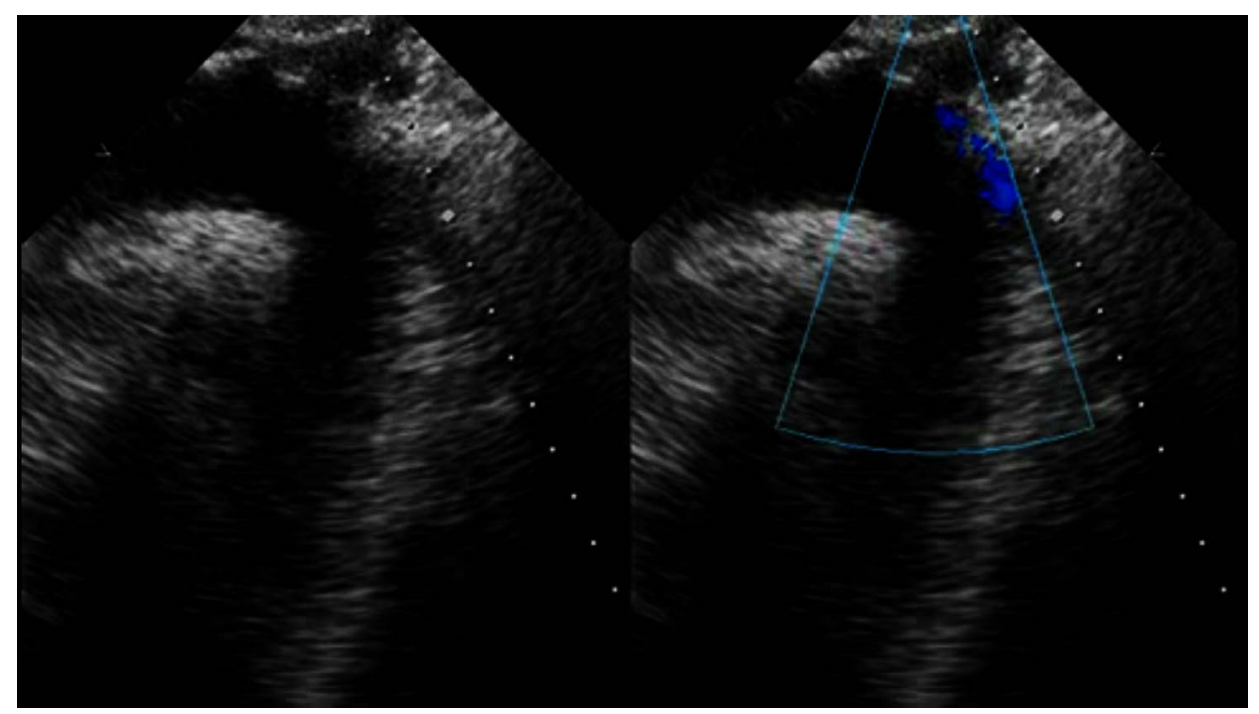

Video 1 Colour comparison of aortic arch from suprasternal view showing no evidence of flap (left) on two-dimensional echo and differential intraluminal flow turbulence on colour doppler (right). 


\section{BMJ Case Reports}

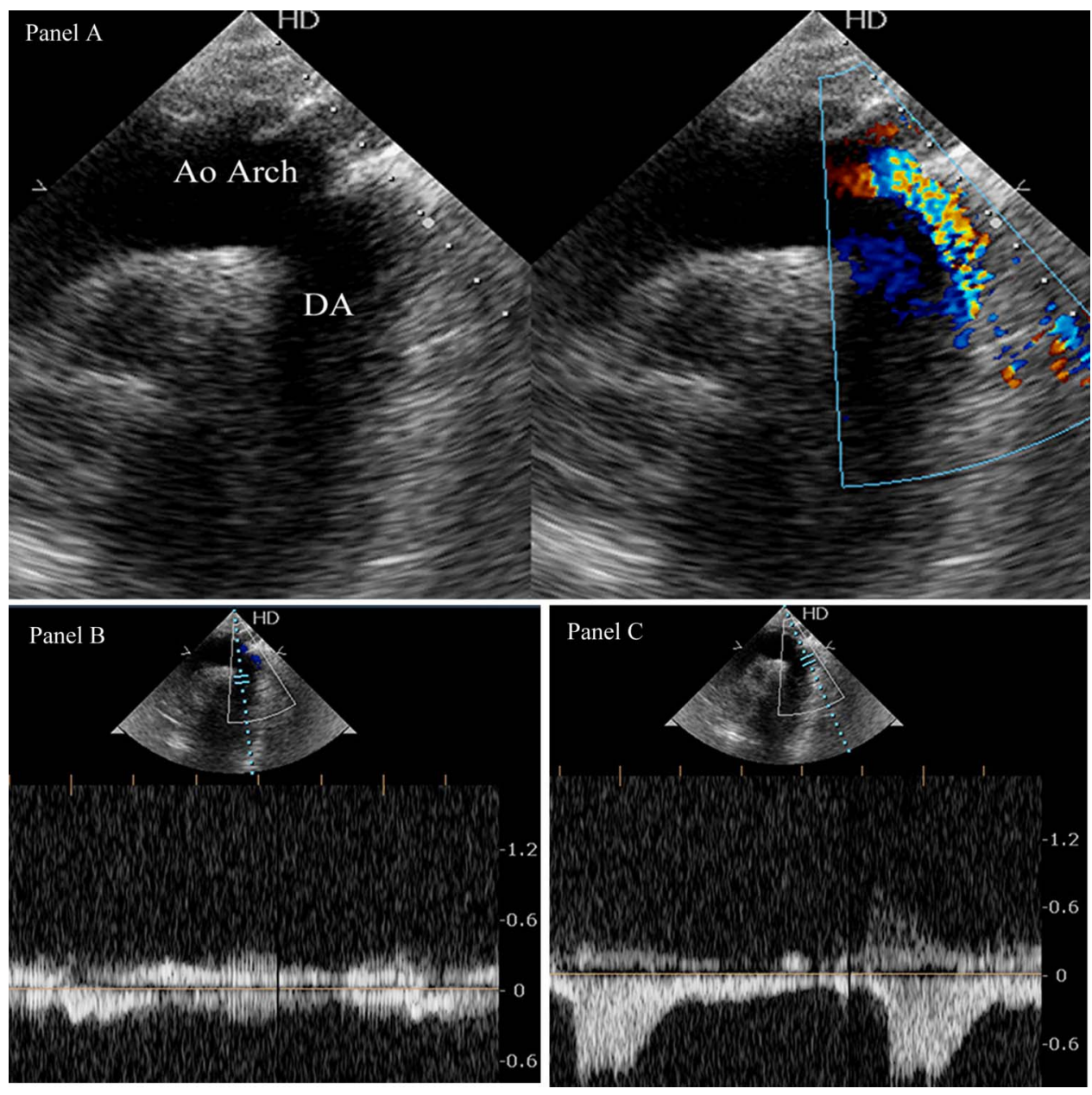

Figure 1 (A) Colour comparison of aortic arch from suprasternal view showing no evidence of flap (left) on two-dimensional echo and differential intraluminal flow turbulence on colour Doppler (right). (B) Pulse Doppler with sample in the centre of the lumen showing sluggish flow. (C) Turbulent forward flow with sample volume over the outer half.
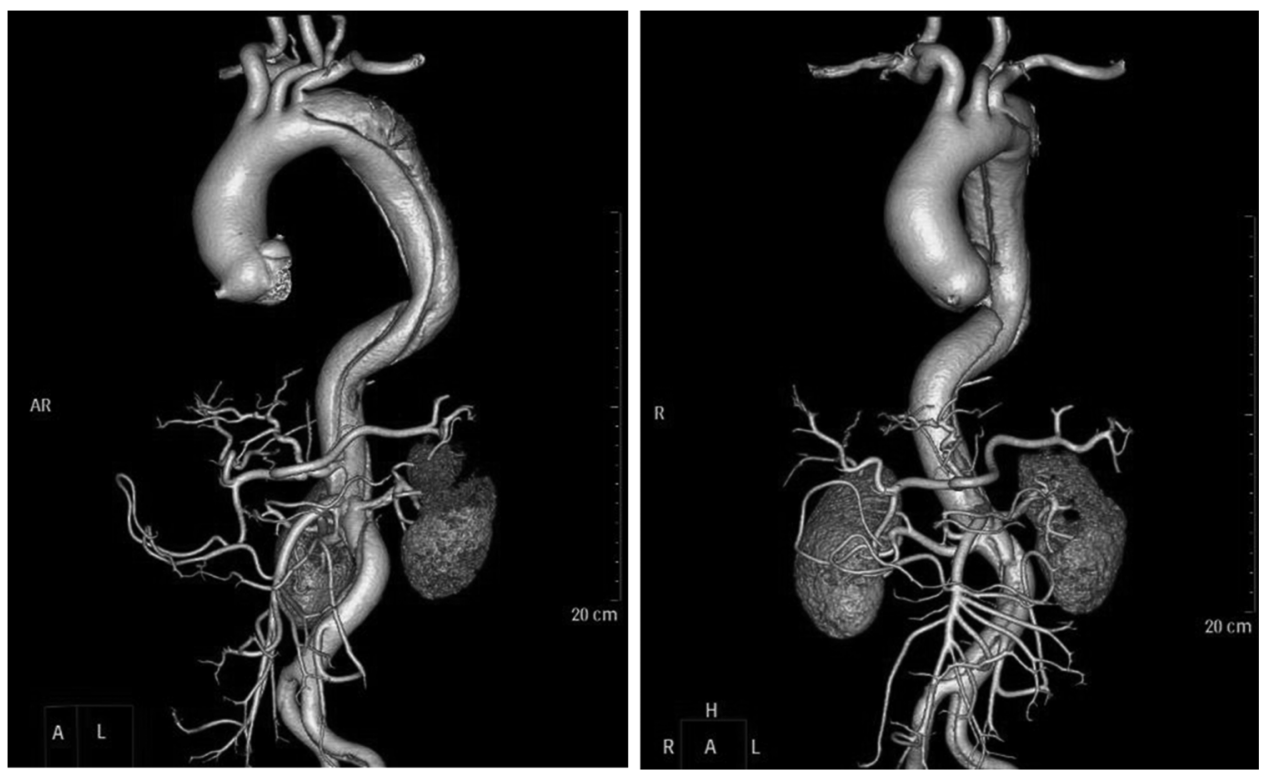

Figure 2 Volume rendered reconstructed CT image showing Stanford type B aortic dissection. 


\section{Learning points}

- High degree of suspicion is needed for diagnosing an aortic dissection.

- Turbulence in the absence of a dissection flap is still suggestive of dissection.

- Transthoracic echocardiogram (TTE) though inferior to TEE could still give some clues of an underlying dissection.
Competing interests None

Patient consent Obtained.

\section{REFERENCES}

1. Ince $\mathbf{H}$, Nienaber CA. Diagnosis and management of patients with aortic dissection. Heart 2007;93:266-70.

Copyright 2012 BMJ Publishing Group. All rights reserved. For permission to reuse any of this content visit http://group.bmj.com/group/rights-licensing/permissions.

BMJ Case Report Fellows may re-use this article for personal use and teaching without any further permission.

Please cite this article as follows (you will need to access the article online to obtain the date of publication).

Rajendran R, Singh B, Bhairappa S, Manjunath CN. Differential intraluminal flow turbulence: a marker of aortic dissection. BMJ Case Reports 2012;10.1136/bcr-2012-007429, Published XXX

Become a Fellow of BMJ Case Reports today and you can:

- Submit as many cases as you like

- Enjoy fast sympathetic peer review and rapid publication of accepted articles

Access all the published articles

- Re-use any of the published material for personal use and teaching without further permission

For information on Institutional Fellowships contact consortiasales@bmjgroup.com

Visit casereports.bmj.com for more articles like this and to become a Fellow 